\title{
Study on Reform of Fine Arts Major Color Courses Teaching
}

\author{
Chunxia Wang
}

Hetao University, Bayannaoer Inner Mongolia, 015000, China

Keywords: College, Painting color, Major courses, Teaching reform.

\begin{abstract}
In college oil painting classroom practice, oil painting color teaching occupies a very important position, and it even can be said that it is the key point of painting art education. In the new era, with the diversified development trend of oil painting art education, traditional teaching concepts and teaching modes have been unable to adapt to modern social talents training needs, and require the combination of teaching needs in the new era for appropriate optimal adjustment of major courses teaching, to ensure the promotion of college oil painting color teaching quality.
\end{abstract}

\section{Introduction}

In traditional teaching practice, although teachers have recognized the importance of color in painting courses teaching, but under the influence of traditional rigid educational philosophy, teachers generally only focus on theory education of color knowledge, but relatively neglect the expression and use of color language and aesthetic education on color in painting, to a certain extent, leading to that most students cannot fully grasp color use techniques during the oil painting creation, and visual impact and artistic appeal of the works are relatively poor, hard to highlight the artistic value of paintings. Colleges and universities must therefore reform painting color courses teaching to provide students with more quality educational services.

\section{Connotation of Oil Painting Color}

The oil painting color is mainly for collocation and use of color and modeling in oil painting creation, and modeling and color are the most basic languages of art in oil painting creation, or even it can be said that oil painting itself is the organic integration of graphic artistic modeling and color art, so in oil painting creation, rational understanding and use of color is very important to enhance artistic expression and visual impact of painting. Mr. Da Vinci had clearly stated in painting color theory, that in the basic composition of the oil painting, there must be some correlation between all colors, and this correlation can promote to achieve the perfect combination of all colors in the same works, to increase the artistic value of the painting correspondingly. Specifically, in creative process, for the rational use of all colors for collocation, large area should choose softer colors, while smaller area uses relatively high-concentration and bright colors, or presented in the way of points. In other words, if we really want to ensure coordination of various colors in the works, it is necessary to achieve a certain balance between all colors in terms of use of color, which is the most basic thought in oil painting color theories ${ }^{[1]}$. These color theories still have certain guidance and high value in oil painting major education in today's society and have been widely recognized in the field of oil painting. For a long time, however, very few people really can comprehend the essence of these seemingly simple theories in practical application, turn these theories into creation practice of oil painting art, or flexibly apply them to oil painting creation, finally resulting in that further development of oil painting art in modern society is subject to certain limitations. Therefore, in colleges oil painting color courses teaching, teachers should pay greater attention to color processing and application to ensure that based on the mastery of the basic application skills, students can innovate the application method with their own understanding, then show their creative characteristics in oil painting process, and enhance connotation and aesthetic taste of oil paintings, to really achieve steady but clear, brilliant but umcommon, and beautiful but tangible application of colors to maximize artistic value of paintings created by students. 


\section{Problems of Current College Traditional Oil Painting Color Courses Teaching}

Color is one of the most important processional languages in oil painting, and also the most basic major courses of college oil painting teaching, with an extremely important influence on training of students' ability to create oil painting. Oil painting color major teaching has some similarities with color teaching of other painting majors in terms of teaching elements, but affected by oil painting teaching features, also has corresponding specialties. At this stage, in our college traditional oil painting color major courses teaching practice, teaching mostly focuses on common sense of color and general skills training, but often lacks emphasis on unique color aesthetic view of oil painting major and special color expression languages training during oil painting creation. Over time, this will inevitably lead to that students can only learn basic painting realistic approaches in oil painting color courses teaching. Students' painting skills can be correspondingly increased, but in fact their painting color application ability cannot be effectively trained ${ }^{[2]}$. Meanwhile, the basic objective of modern art education and art creation in the new era has begun to change to some extent, traditional single artistic concept has gradually been transformed into diversified model coexisting with the times, and oil painting art creation ideas and artistic norms are also adjusted. From the overall development trend, under the current social impact, oil painting art teaching also shows the diversified development trend to some degree and teaching content and connotation have been deeply adjusted. Traditional oil painting color major courses teaching has been difficult to adapt to the current diversified times development, and it is necessary to reform and innovate major courses teaching, and adjust and optimize oil painting color major teaching, in order to promote oil painting color teaching gradually to meet needs of the current oil painting talents training and provide appropriate protection for the good development of China's oil painting.

\section{Reform of Oil Painting Color Major Courses Teaching}

\section{Positively change traditional educational teaching concepts.}

First, in teaching practice, teachers should further strengthen emphasis on artistic individual work of students, and must specify that students are the subject of teaching activities. And affected by ideological differences, students' understanding of colors in life is different and color sensitivity in oil painting process and feelings and emotions with colors change are also often different to some degree, therefore, in order to further enhance the effectiveness of teaching, teachers should combine with individual differences of students for targeted teaching ${ }^{[3]}$. In fact, the essence of art is to enrich the connotation of artistic works by means of differences and innovation expressed by different creators, and constant exploration on differences for innovation is also the essential reason for diachronic heritage and development of art. Therefore, in the teaching practice, teachers are necessary to positively change the traditional education concept, really take training art creative personality and creativity of students as the most important teaching objective, and endeavor to train students into high-quality artistic talents.

Second, for change of teaching concept, teachers should also strengthen training of students' comprehensive quality of color applications. Diversified development trend of art education has prompted the society to put forward higher requirements on overall quality of students, and in college traditional color courses teaching, training of students' color expression ability and overall quality has been unable to meet the current social talent demand, therefore, teachers should also follow the trend of the times and actively change education concepts, and train students to have more complete color overall quality. Specifically, in oil painting color courses teaching, teachers should enable students to not only master basic color application knowledge and general skills, but also focus on control and application ability of oil painting colors, to promote and upgrade their color creation ability in the long-term learning process. Only in this way can oil painting color teaching really play an important role and students' oil painting creation ability can be truly enhanced.

\section{Reasonably innovate teaching methods.}

Teachers can innovate oil painting color courses teaching methods from the following aspects. 
First, guide students to well combine the theory learning and practical operations. For college oil painting color courses teaching, after students generally complete the one-period systematic learning, they can have corresponding perceptual knowledge for oil painting creation. And this perceptual knowledge is the basis for further learning. For example, after a period of learning and corresponding oil painting color training, students can coordinate dark and bright portions in color application, and space expression between the distant and nearby, the relationship between large and small patches, and form preliminary emotional awareness. And reasonably converting such perceptual knowledge into authoring experience necessarily requires teachers to educate and guide ${ }^{[4]}$. Therefore, in particular teaching process, teachers should help students to sort out and summarize perceptual knowledge obtained in learning, and guide students to verify in the next stage of practical learning, so that students can complete internalization of theoretical knowledge in practice, to further enhance their own color application ability in oil painting creation.

Second, pay enough attention to the application of the comprehensive material in oil painting color courses teaching. The development of modern oil painting creation has been showing a clear trend of diversification, therefore, in the current times, traditional single technique material of oil painting color teaching will be inevitably replaced by the comprehensive technique material. So in the future, we must strengthen the application of the comprehensive material in future teaching practice, prompt the application of comprehensive material to further promote training of students' innovative ability, to maximize the application value of comprehensive material in oil painting color courses teaching.

Third, use computer multimedia equipment to carry out teaching activities. In oil painting creation, within the constraints of traditional creative conditions, color expression generally only can take the actual colors as the carrier, and the development of computer technology and the advent of the computer era provide a new medium for color expression in oil painting creation. In traditional teaching, the actual paint color performance can further enhance students' practical ability, but there are some problems, such as high cost and low efficiency of education, and deployment of color saturation also has a certain effect on the expression of oil painting color languages. And the use of computer technology can solve this problem. The rational application of computer technology can not only get rid of shortcomings of traditional pigment teaching, but also train students' interest in learning, to further promote teaching efficiency, and help turn training students' practical ability into exercising their thinking ability and creative ability, which is conducive to further enhancement of the teaching effectiveness. Therefore, teachers should pay more attention to the application of computer in oil painting color teaching, and fully exerting the helping role of the computer.

Finally, strengthen the emphasis on deconstruction and integration work of traditional national colors. Chinese traditional national colors are the inexhaustible important resource for color performance in Chinese oil painting art, so teachers should strengthen the emphasis on deconstruction and integration work of traditional national colors in oil painting color courses teaching, in particular combining with traditional teaching needs to draw the essence of national colors, combining with modern colors for use in artistic creation, and increasing students' ability of color appreciation and integration.

\section{Scientifically optimize and adjust courses setting.}

Scientific and rational course setting has a decisive influence on enhancing the quality of teaching. In our college traditional oil painting color teaching, course setting often adopts the following way. In all grade levels, set appropriate basic courses, including character color, human body color, still life color and landscape color sketching, paying more emphasis on learning and training of students, able to play a certain effect on teaching ${ }^{[5]}$. However, this way is single, not conducive to enrich students' extracurricular knowledgeable and train their comprehensive ability, therefore, it is necessary to scientifically optimize and adjust traditional courses setting, to lay the foundation for training high-quality oil painting talents.

Meanwhile, in college traditional oil painting color major courses, in addition to the lack of scientific and rational course setting, single teaching mode used by teachers also needs further adjustments. Teachers should use high-quality teaching mode to ensure the subjectivity and creativity 
of students appropriately exerted. At this stage, based on the diversification development trend of creative concepts in oil painting artistic creation and co-existence of figurative, imagery and abstract characteristics demonstrated through artistic design languages, in order to obtain a better development, oil painting color major teaching must also abandon the traditional simplified teaching mode, conform to the trend of the times for reform and innovation, and optimize and adjust major courses teaching, to provide the appropriate guarantee for training of high-quality oil painting artistic talents. Overall, based on strengthening basic courses construction work, oil painting color major teaching should also combine with the times demand for optimization and innovation of new courses construction, and truly create a more scientific, rational and complete education system, to meet the learning needs of students, and also further enhance college oil painting color major teaching quality.

\section{Conclusions}

In summary, oil painting color plays an extremely important role in oil painting creation, therefore college teachers should pay greater attention to color teaching in oil painting courses teaching, conduct reasonable teaching reform, to train students' color application ability and aesthetic ability, and greatly enhance artistic expression, appeal and visual impact on the viewer of students' oil painting works, and gradually increase the artistic value of students' oil painting creation, train students into high-quality artistic talents, and also ensure their better development in the future.

\section{References}

[1] Yang Xianping, Wu Shihua. On Reform and Innovation of Oil Painting Color Teaching, Sichuan Theatre, 2011 (5): 143-144.

[2] Gao Yang. Practice and Reflection of College Oil Painting Color Teaching, Industry and Science Forum, 2014 (24): 152-152,153.

[3] Tang Qin. Study on Application of Freehand Painting Technique in Oil Painting Color Teaching , Decision and Information (LAST), 2015 (5): 76-76.

[4] Liu Yuxia. Again on Reform and Innovation of Oil Painting Color Teaching, Course Education Research (new teachers teaching), 2012 (15): 164.

[5] Ma Ke. Practice and Reflection of College Oil Painting Color Teaching, Knowledge Guide, 2015 (19): 119-119. 